\title{
Differentiation Between Spirits According to Their Botanical Origin
}

\author{
Paulina Wiśniewska $^{1}$ - Magdalena Śliwińska ${ }^{1}$ - Tomasz Dymerski ${ }^{1}$. \\ Waldemar Wardencki ${ }^{1}$ • Jacek Namieśnik ${ }^{1}$
}

Received: 11 May 2015 / Accepted: 6 August 2015 /Published online: 16 August 2015

(C) The Author(s) 2015. This article is published with open access at Springerlink.com

\begin{abstract}
Agricultural distillates are used for the production of spirit beverages. As more and more products with a specific botanical composition specified on the label are produced (e.g. rye vodkas, wheat vodkas and Polish Vodka, which cannot be produced with the addition of maize distillate), it is necessary to look for quicker and more accurate methods allowing the determination of botanical origin of alcoholic beverages and materials used to their production. The aim of this study is to verify the usefulness of the electronic nose based on the ultra-fast gas chromatography for quick differentiation between agricultural distillates according to their botanical origin. Nineteen samples included distillates from rye, triticale, wheat and maize were used for the research. For data analysis, the following methods were used: PCAPrincipal Component Analysis, DFA-Discriminant Function Analysis, SIMCA classification (SIMCASoft Independent Modeling of Class Analogies) and SQC-Statistical Quality Control. The use of the electronic nose with ultra-fast gas chromatography and the use of DFA and SIMCA analyses allowed differentiation between agricultural distillates according to their botanical origin.
\end{abstract}

Keywords Raw spirits $\cdot$ Electronic nose $\cdot$ Botanical origin . Fast gas chromatography

Paulina Wiśniewska

p.m.wisniewska@gmail.com

1 Department of Analytical Chemistry, The Chemical Faculty, Gdansk University of Technology, 11/12 Narutowicza St, 80-233 Gdansk, Poland

\section{Introduction}

According to Regulation No. 110/2008 of the European Parliament and of the Council (EC) of 15 January 2008, a distillate of agricultural origin means an alcoholic liquid, which is obtained by the distillation, after alcoholic fermentation, from specific agricultural products, which do not has the characteristics of ethyl alcohol or a spirit drink, but still retains the odour and flavour of the ingredients used. The regulation defines the minimum alcoholic strength by volume, which should be $96.0 \%$ vol., and the maximum levels of some compounds, such as esters up to $1.3 \mathrm{~g} / \mathrm{hl}$ of alcohol $100 \% \mathrm{vol}$. (expressed in grams of ethyl acetate), aldehydes $0.5 \mathrm{~g} / \mathrm{hl}$ (expressed in grams of acetaldehyde), higher alcohols $0.5 \mathrm{~g} /$ $\mathrm{hl}$ (expressed in grams of 2-methyl-1-propanol) and methanol $30 \mathrm{~g} / \mathrm{hl}$.

The composition of agricultural distillates is influenced by the material, from which it is produced and fermentation conditions, including, amongst other things, tanks, in which this process is conducted and the distillation process (Tarko 2006). During the fermentation process conducted using yeasts, volatile and non-volatile by-products are produced, apart from ethanol, which influence the quality of the alcohol. Nonvolatile substances, which remain in the dry mass of the mash, include sugars which have not been fully fermented, cellulose, substances containing nitrogen compounds, and mineral salts. Non-volatile substances, which remain in the brew, include glycerine and acids, e.g. lactic acid. Volatile substances, which enter the distillate as by-products, can include the following groups of compounds: methanol, higher alcohols, esters, fatty acids, carbonyl compounds, i.e. aldehydes, ketones, acetals and other (Tarko 2006; Stanisz et al. 2009). As previously mentioned, the concentrations of these products largely depend on the material, from which the distillate is produced. Raw spirits can be produced from different materials like 
grain, potato, beet, sugar cane, molasses or other products contain starch. In the industry, agricultural distillates produced for human consumption are usually made from grains or potato. Each of the distillate differs in composition due to materials from which they are made. For example, raw spirits obtained from triticale contain relatively small amounts of acids, esters, methanol and higher alcohols, as compared to rye distillates (Pietruszka et al. 2010).

Ethanol is the main component of the matrices of agricultural distillates; however, apart from it, these matrices are characterised by the presence of a large number of compounds at low concentrations originating from various groups. As a result, tests of the composition of agricultural distillates are not easy, due to legal requirements (Tarko 2006), which must be complied with so that a distillate can be used for the production of spirit beverages and also due to the large number of compounds influencing the quality of spirits. It is very important that research should be conducted, which will allow for defining characteristic features of spirits and for assessing the quality of the products and their processing. Research is usually conducted using gas chromatography to determine the composition of specific compounds or a group of compounds (determination of aldehydes in raw spirits made from potato (Czupryński and Kotarska 2009), esters in grain distillates (Plutowska and Wardencki 2008) and quality assessment of grain spirits (Plutowska et al. 2010; Wardencki et al. 2009)). Attempts have been also made to distinguish between agricultural distillates according to their botanical origin using gas chromatography by Jeleń et al. 2010 (raw spirits made from rye, potato and corn), Ziółkowska and Jeleń 2012 (agricultural distillates produced from rye, corn and potato) and Biernacka and Wardencki 2012 (raw spirits made from rye, corn, wheat and triticale); however, they did not allow for accurate differentiation between all tested distillates and the method itself was relatively long. As more and more products with a specific botanical composition specified on the label are produced (e.g. rye vodkas, wheat vodkas and Polish Vodka, which cannot be produced with the addition of maize distillate), it is necessary to look for quicker and more accurate methods allowing the determination of botanical origin.

The aim of this study is to verify the usefulness of the electronic nose based on the ultra-fast gas chromatography Heracles II form Alpha MOS Co. (Toulouse, France) for quick differentiation between agricultural distillates according to their botanical origin. The results of this study may contribute to the development of quality control of products and a more efficient assessment of materials for the production of spirit drinks with a composition specified on the label. Conducted research improves a product authentication for such alcohols as Polish vodkas, which in the near future can constitute a background for supplementation of law regulations or be a basis of the new ones.

\section{Materials and Methods}

\section{Materials}

Agricultural distillates obtained from Destylarnia Sobieski S.A. (Poland, Pomeranian Province) and the Żyrardów distillery (Poland, Mazovian Province) were used for analysis. Distillates were produced in the smaller breweries located across whole area of Poland, namely they were from Kołaczkowo, Jawty Wielkie, Lotyń, Rąbczyn, Brzostowo, Skrzatusz, Wielka Klonia, Kęsowo and then delivered to the above-mentioned distilleries. The samples included distillates from three rye cultivars (eight samples), two triticale cultivars (four samples), three wheat cultivars (three samples) and two maize cultivars (four samples). All of distillates, which have been used, were good quality.

\section{Methods}

\section{Sample Preparation}

All samples were prepared using the same analytical procedure. This is connected with similar ethanol concentrations in the tested samples and a similar composition of materials used for the production. About $6.25 \mathrm{ml}$ of water and $1.75 \mathrm{ml}$ of agricultural distillate were added to the vial. Next, the samples were mixed and analysed using the electronic nose. Depending on the amount of the sample, three or two repetitions were performed.

\section{Electronic Nose Analysis}

An electronic nose based on ultra-fast gas chromatography by Alpha MOS (Toulouse, France) was used for the research. It is equipped with a sorption trap, a dispenser allowing for the introduction of a gas or liquid sample, two flame ionisation detectors (FID), dedicated AlphaSoft V12 software with implemented modules for chromatographic, chemometric, and sensory analysis of characteristics of detected chemical compounds, the Arochembase V4 HERACLES V12 library, an HS100 autosampler, a set of independent chromatographic columns with different polarity (non-polar MXT-5 and medium polar MXT-1701, length $10 \mathrm{~m}$ ). For the autosampler, the incubation time was set at $1200 \mathrm{~s}$, the incubation temperature at $40{ }^{\circ} \mathrm{C}$ and the syringe temperature at $100^{\circ} \mathrm{C}$. About $2.5 \mathrm{ml}$ of the sample were dispensed for $5 \mathrm{~s}$ at the dispenser temperature of $200{ }^{\circ} \mathrm{C}$ with the volumetric intensity of the carrier gas flow equal to $30 \mathrm{ml} / \mathrm{min}$. The sample was kept at the sorption trap for $20 \mathrm{~s}$ at $40^{\circ} \mathrm{C}$. The analysis started at $40{ }^{\circ} \mathrm{C}$ for $2 \mathrm{~s}$, and next, an increase in the temperature of $3{ }^{\circ} \mathrm{C} / \mathrm{s}$ was used until a temperature of $270^{\circ} \mathrm{C}$ was reached, which was maintained for 18 s. Hydrogen was used as the carrier gas. The following chemometric methods were used for proper data 


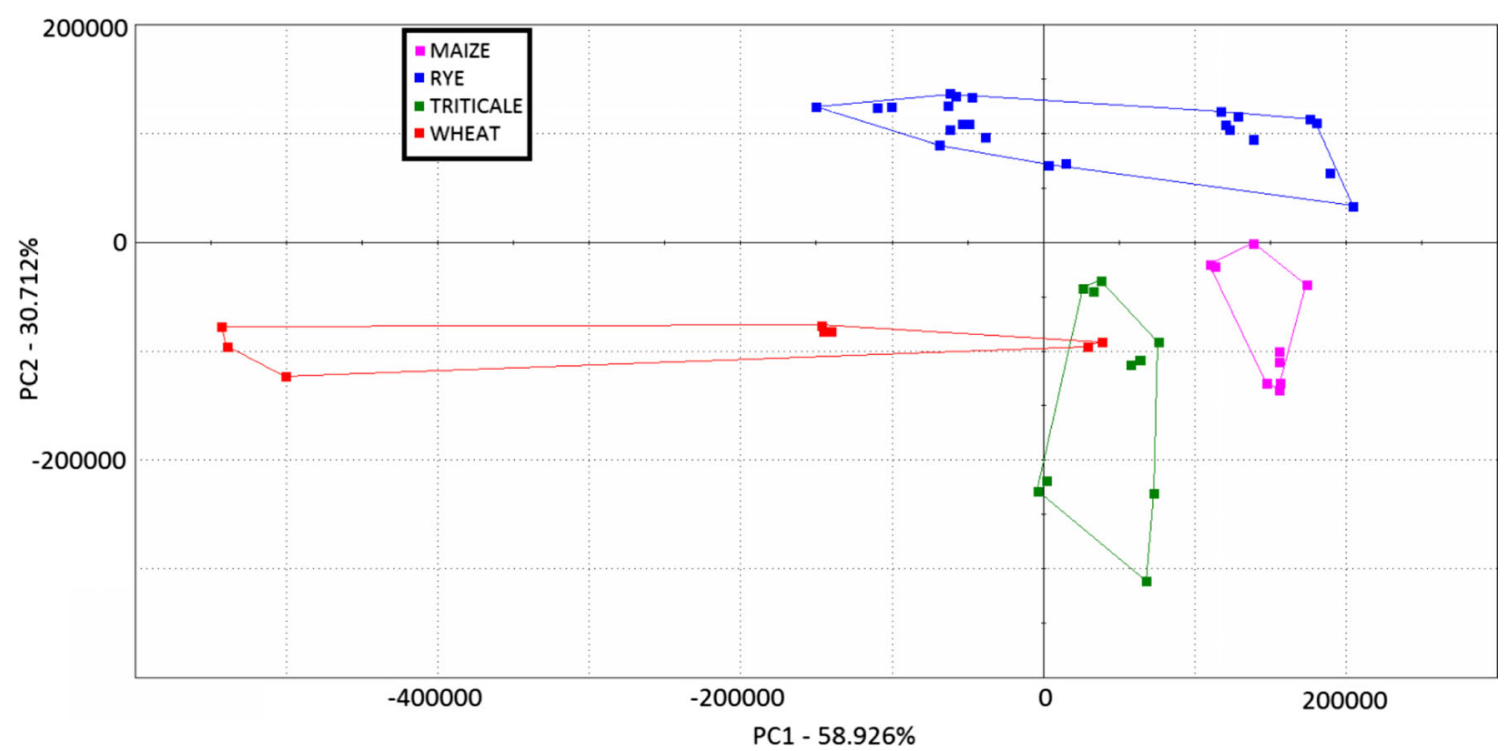

Fig. 1 PCA scores of agricultural distillates

interpretation: PCA — Principal Component Analysis, DFADiscriminant Function Analysis, SIMCA classification (SIMCA - Soft Independent Modeling of Class Analogies) and SQC — Statistical Quality Control.

\section{Chemometric Methods}

The PCA is mainly used for modeling, compressing and the visualization of multivariate data. This method of data analysis involves the reduction of the number of variables describing samples or finding relationships between them. This method of data analysis presents the variability in the data structure transforming it into a new system of coordinates, where the number of coordinates will be less than the number of original variables. Transformations of variables are based on the fact that a new set of variables is created by a fewer variables, but at the same time a maximum variability of the dataset is achieved. After transformation, coordinates are called the principal components (Mazerski 2000).

The principle of DFA is to determine which variables allow to differentiate the samples into indicated groups. Subsequently, these variables are used to classify the unknown samples. This method comprises two main steps, namely first step - a step of learning or building a model, which relies on finding classification rules based on a training set of data, and second one - a classification step or the use of a model which

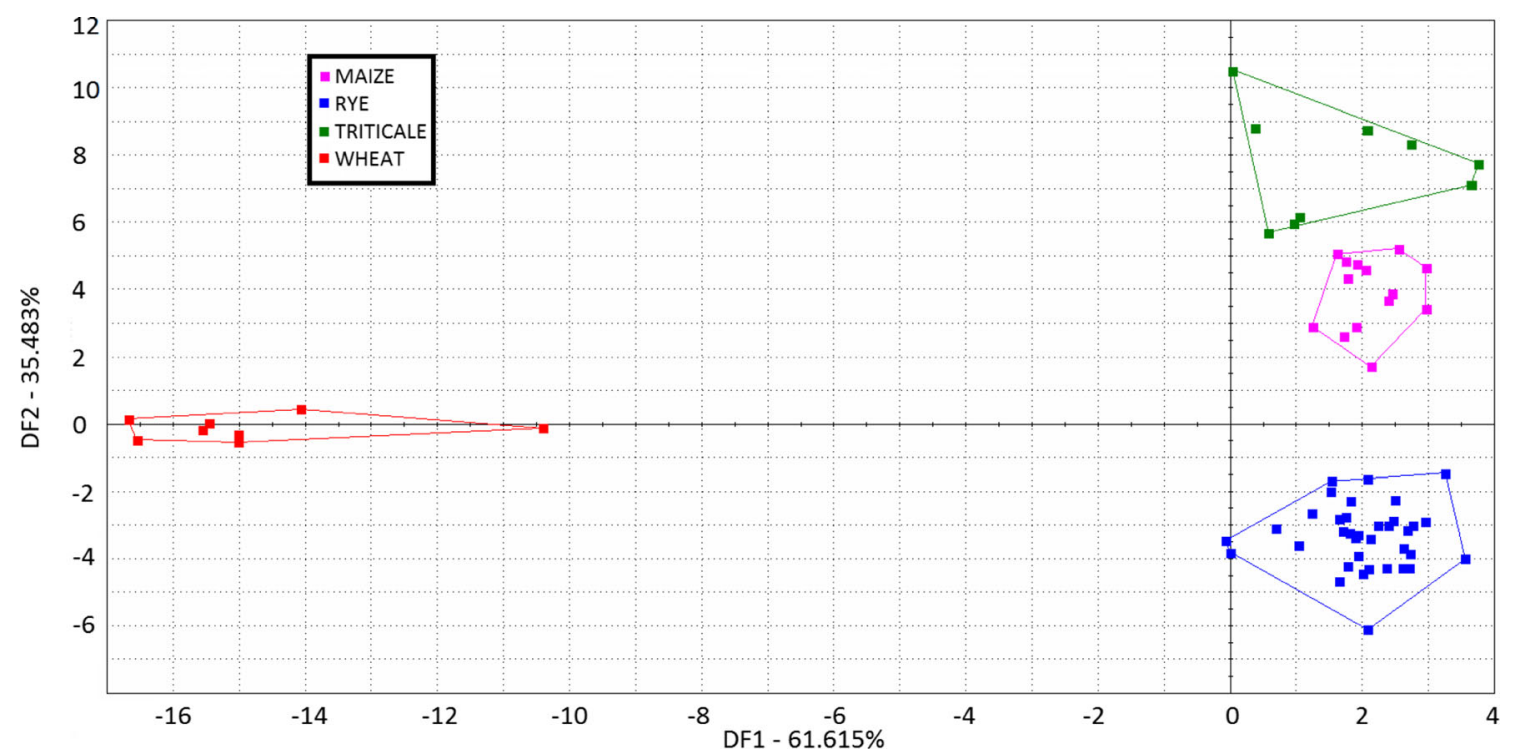

Fig. 2 DFA scores of agricultural distillates 


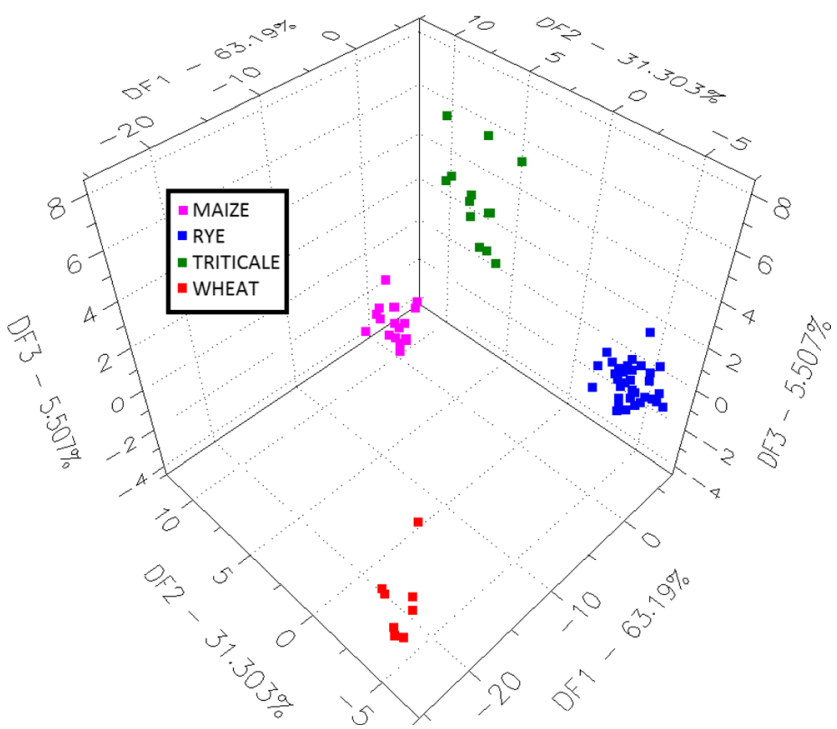

Fig. 3 Three-dimensional DFA scores of agricultural distillates

is based on the classification rules obtained in first step (Mazerski 2000).

The SIMCA analysis is based on PCA models which are created for all the objects in the first stage of the analysis. Subsequently, each of class is calculated using a separate PCA model, which contains the optimum number of the main components defining the data structure. Classification is carried out in two stages. The second stage is called the stage of testing. It is based on the assignation of new objects to existing class with the best fit. The results of the classification depend on the choice of the number of principal components of model class (Wójcicki 2013).

The SQC analysis is usually used for quality control of processes. Samples, which belong to one group, should be related to the designated area of the graph. These parameters include deviations from the target samples or concentrations of tested substances. If unknown samples are not related to the designated area, it means they are statistically different with the samples assigned to the reference group (Karkalousos and Evangelopoulos 2011).

\section{Results and Discussion}

All samples were first analysed using PCA to verify the usefulness of this method for distinguishing between distillates according to their botanical origin. This analysis allows data visualisations, owing to which it can be defined which samples differ the most from those found in the created group.

PCA did not allow full differentiation between the tested distillates according to their botanical origin (Fig. 1). Two points belonging to one sample of a wheat distillate situated between $\mathrm{PC} 1=25,000$ and 50,000 overlapped with a group of points belonging to distillates produced from triticale situated between $P C 1=0$ and 100,000 . It is probably caused by smaller differences in the composition of wheat distillates and those produced from triticale, which is connected with the fact that triticale is a hybrid of wheat and rye. It should be noticed that the points are not dense in any of the tested groups. This is probably connected with various production processes of the tested distillates and the use of various cultivars for their production. Due to the lack of full differentiation, it is necessary to use another chemometric method to distinguish between agricultural distillates according to the tested materials.

DFA was another method used - this analysis is used for grouping data and differentiating between groups.

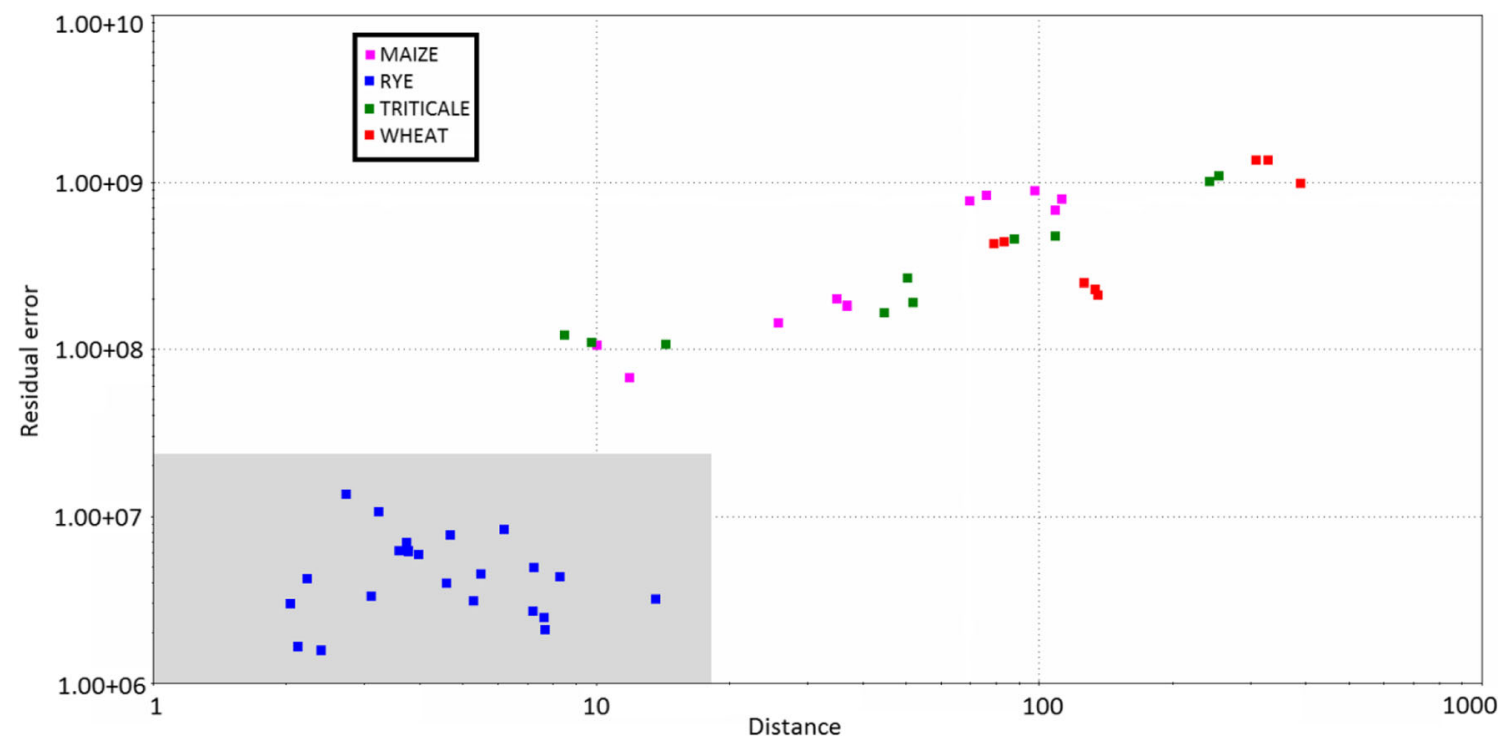

Fig. 4 SIMCA scores of agricultural distillates; agricultural distillates from rye - a reference group 


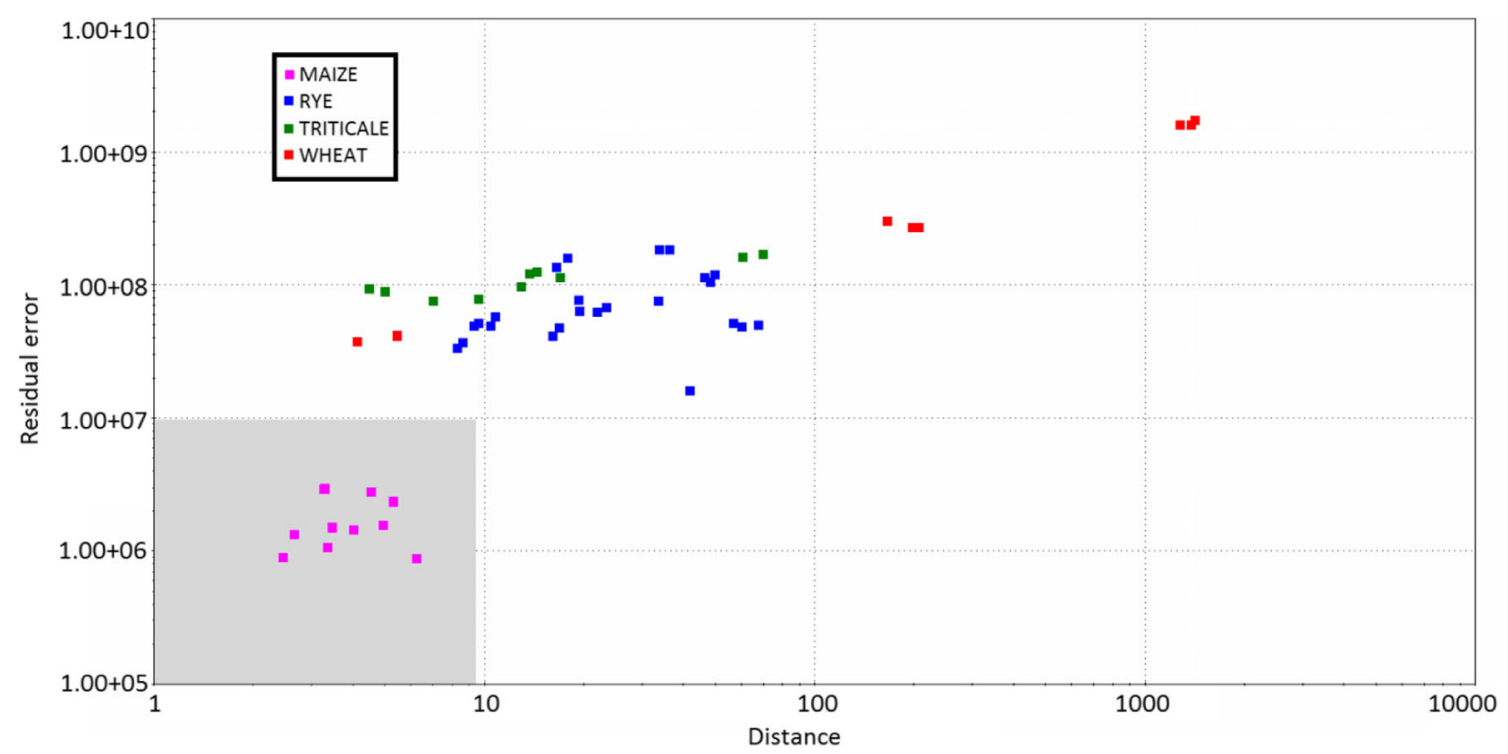

Fig. 5 SIMCA scores of agricultural distillates; agricultural distillates from maize - a reference group

Figures 2 and 3 present DFA graphs. DFA allowed for distinguishing between all tested groups of agricultural distillates. Points belonging to wheat distillates are situated between DF $1=-17$ and -10 on the DFA graph, while the points belonging to others groups are situated between $\mathrm{DF} 1=-1$ and 4. Group of points belonging to triticale distillates are situated between $\mathrm{DF} 1=0$ and $10, \mathrm{DF} 2=5$ and $12.5, \mathrm{DF} 3=0$ and 6 , group of points belonging to maize distillates are situated between DF1 $=-5$ and $10, \mathrm{DF} 2=7.5$ and $12.5, \mathrm{DF} 3=-6$ and 0 , which is shown on the $3 \mathrm{D}$ graph (Fig. 3). These groups are the closest to each other on the DFA graph. Due to small distances between points on the DFA graph, it was necessary to check other available chemometric methods.

In SIMCA classification, a separate graph is created for each reference group. Groups are created on the basis of the principal component method. Next, the so-called "confidentiality envelope" is created around them, which should include, with defined probability, all elements contained in a given class. Four graphs were prepared for each group of distillates as a reference group.

It can be noticed in graphs presented in Figs. 4, 5, 6 and 7 that the so-called "confidentiality envelopes" contain only points, which belong to reference groups, i.e. groups, for which a given graph was created. All points belonging to other groups are outside the designated area. This means that the selected method proved to be successful in the differentiation between the tested groups of agricultural distillates.

The SQC analysis allowed for distinguishing only one group of points belonging to rye distillates. The other groups of points were characterised by too great differences between

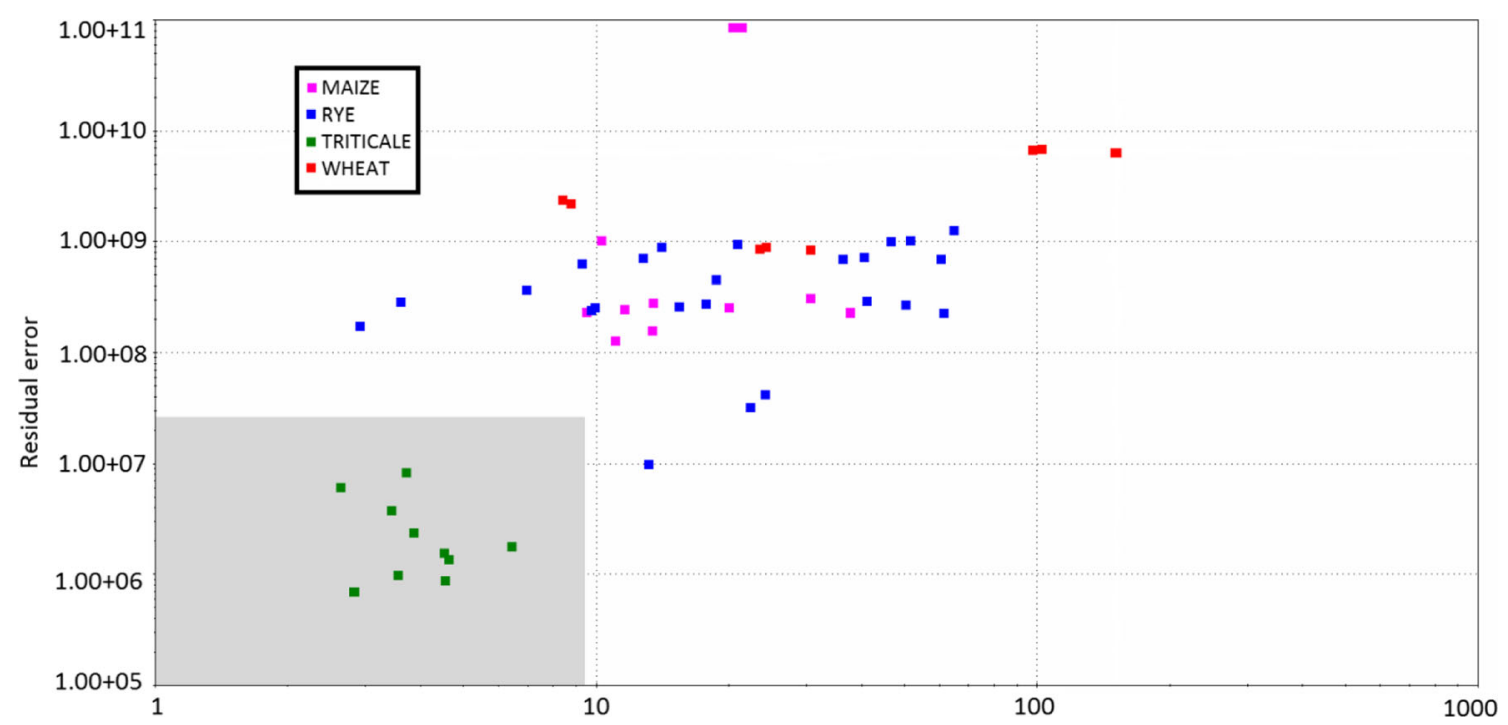

Fig. 6 SIMCA scores of agricultural distillates; agricultural distillates from triticale — a reference group 


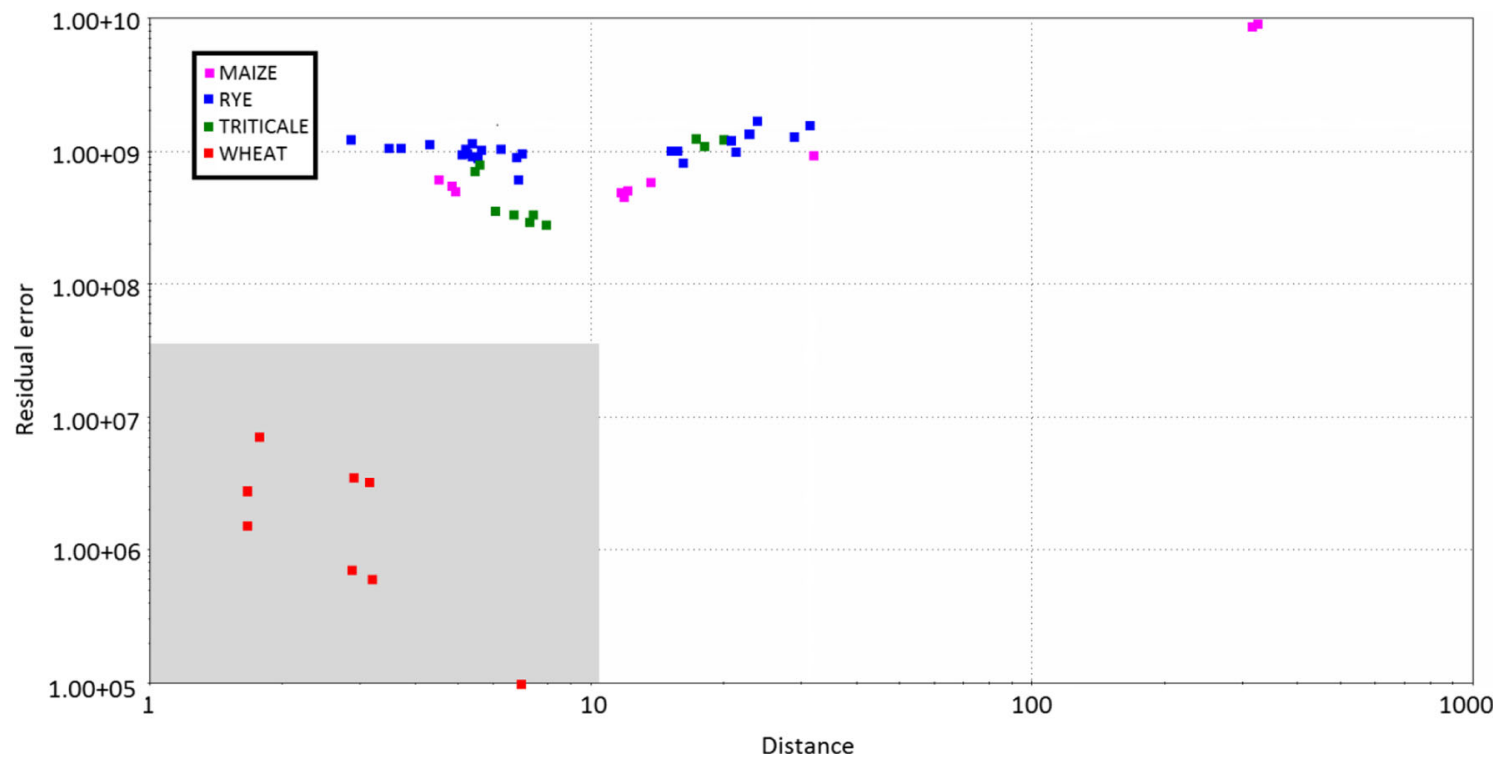

Fig. 7 SIMCA scores of agricultural distillates; agricultural distillates from wheat - a reference group

points belonging to individual groups. This is probably connected with different production processes and the use of various cultivars of the cereal in question. Apparently, rye cultivars used for the production of rye distillates are characterised by high similarity, as a result of which points belonging to rye distillates on the SQC graph overlap at close distances from each other (Fig. 8).

\section{Conclusion}

Due to changing legal regulations, it is more and more often required that the materials needed for the production of alcohols obtained from agricultural distillates should be specified. To meet the demand, the usefulness of the electronic nose using ultra-fast gas chromatography for the assessment of the botanical origin of agricultural distillates was tested. This device is characterised by simplicity and the ability to conduct quick analyses, which last several dozen or several hundred seconds. Four chemometric methods were used for data analysis: PCA, DFA, SIMCA and SQC. From these methods, DFA and SIMCA allowed the differentiation between all tested groups of agricultural distillates. In PCA, the differentiation between distillates produced from triticale and those produced from wheat proved to be impossible. The SQC analysis, on the other hand, only allowed differentiation between rye distillates and the other distillates used in the analysis. In summary, the use of the electronic nose with ultra-fast gas chromatography and the use of chemometric DFA and SIMCA analyses allowed differentiation between agricultural distillates

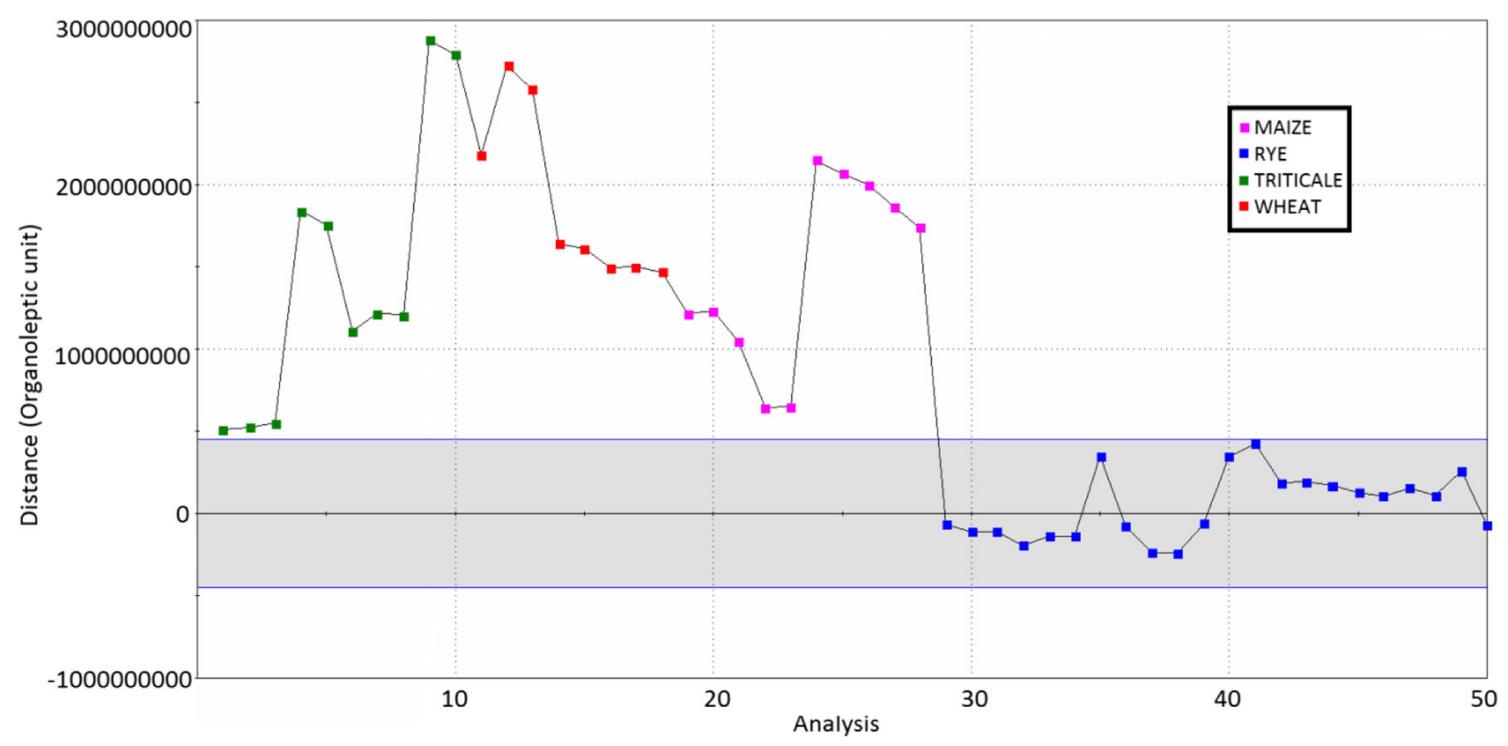

Fig. 8 SQC scores of agricultural distillates; agricultural distillates from rye - a reference group 
according to their botanical origin. The results of this study can be used for quality control and authentication in the food industry. The elaborated procedure allows to control the raw material delivered to the distilleries and consequently to reduce the adulteration of products appearing on the market. Moreover, the information about of the origin of these alcohols is achievable, thus the certification in accordance with legal regulations for such alcohols as Polish Vodkas will be also possible.

\section{Compliance with Ethical Standards}

Funding Financial support for this study by the Grant No.2012/05/B/ ST4/01984 from National Science Centre of Poland.

Conflict of Interest Paulina Wiśniewska declares that she has no conflict of interest. Magdalena Śliwińska declares that she has no conflict of interest. Tomasz Dymerski declares that he has no conflict of interest. Waldemar Wardencki declares that he has no conflict of interest. Jacek Namieśnik declares that he has no conflict of interest.

Ethical Approval This article does not contain any studies with human participants or animals performed by any of the authors.

Informed Consent Not applicable.

Open Access This article is distributed under the terms of the Creative Commons Attribution 4.0 International License (http:// creativecommons.org/licenses/by/4.0/), which permits unrestricted use, distribution, and reproduction in any medium, provided you give appropriate credit to the original author(s) and the source, provide a link to the Creative Commons license, and indicate if changes were made.

\section{References}

Biernacka P, Wardencki W (2012) Volatile composition of raw spirits of different botanical origin. J Inst Brew 118:393-400
Czupryński B, Kotarska K (2009) Zanieczyszczenia chemiczne spirytusów surowych związkami karbonylowymi, Inż. Ap. Chem 48:031-032

Jeleń HH, Ziółkowska A, Kaczmarek A (2010) Identification of the botanical origin of raw spirits produced from rye, potato, and corn based on volatile compounds analysis using a SPME-MS method. J Agric Food Chem 58:12585-12591

Karkalousos P, Evangelopoulos A (2011) Quality Control in Clinical Laboratories. IOP Publishing INTECH. http://cdn.intechopen.com/ pdfs-wm/14849.pdf. Accessed 07 July 2015

Mazerski J (2000) Podstawy chemometrii. Gdansk University of Technology, Gdańsk

Pietruszka M, Pielech-Przybylska K, Szopa JS (2010) Synthesis of higher alcohols during alcoholic fermentation of rye mashes Zeszyty Naukowe. Chemia Spożywcza i Biotechnol/Politechnika Łódzka 1081:51-64

Plutowska B, Wardencki W (2008) Determination of volatile fatty acid ethyl esters in raw spirits using solid phase microextraction and gas chromatography. Anal Chim Acta 613:64-73

Plutowska B, Biernacka P, Wardencki W (2010) Identification of volatile compounds in raw spirits of different organoleptic quality. J Inst Brew 116:433-439

REGULATION (EC) No 110/2008 OF THE EUROPEAN PARLIAMENT AND THE COUNCIL of 15 January 2008 on the definition, description, presentation, labelling and protection of geographical indications of spirit drinks and repealing Council Regulation (EEC) No 1576/89

Stanisz M, Sapińska E, Pielech-Przybylska K (2009) Charakterystyka zanieczyszczeń występujących w spirytusach surowych. Zeszyty Naukowe. Chemia Spożywcza i Biotechnol/Politechnika Łódzka 1058:105-121

Tarko T (2006) Komponenty aromatu napojów alkoholowych. Lab 11: $39-42$

Wardencki W, Chmiel T, Dymerski T, Biernacka P, Plutowska B (2009) Application of gas chromatography, mass spectrometry and olfactometry for quality assessment of selected food products. Ecol Chem Eng 16:287-300

Wójcicki K (2013) Zastosowanie wybranych technik spektroskopowych do oceny jakości olejów roślinnych. Dissertation, Poznań University of Economics

Ziółkowska A, Jeleń HH (2012) Differentiation of raw spirits of rye, corn and potato using chromatographic profiles of volatile compounds. $\mathrm{J}$ Sci Food Agric 92:2630-2637 